\title{
Comparative Study on the Effect of Psychomotricity and Soccer on Withdrawn Behavior of Students with Intellectual Disabilities
}

\author{
Youn Tae Suh, Jin Ho Ryu* and Jae Goon Jung \\ Department Adapted of Physical Education, Hanshin University, Osan, 18101, Republic of Korea; syt@hs.ac.kr, \\ bkjh21@naver.com, hanwoori0119@hanmail.net
}

\begin{abstract}
Objectives: To investigate the effect of psychomotricity programs and soccer programs on withdrawn behavior of students with intellectual disabilities in an integrated environment. Methods: Subjects were divided into two groups, the psychomotricity group and the soccer group, each consisting of 12 children. Programs were conducted twice a week for 12 weeks from Mar. 30 to Jun. 30, 2015, and tests on the children's withdrawn behavior were conducted before and after the programs. Both programs were carried out in the integrated environment. SPSS 18.0 program was used to analyze the data ${ }^{*} \mathrm{p}<.05$. Findings: Analysis on withdrawn behavior of the subjects in peer relations showed a significance difference in the psychomotricity group, while no meaningful difference was found for the soccer group. Analysis on withdrawn behavior of the subjects in communication showed a significance difference in the psychomotricity group, while no meaningful difference was found for the soccer group. Analysis on withdrawn behavior of the subjects in self-esteem showed a significance difference in the psychomotricity group, while no meaningful difference was found for the soccer group. Tests on withdrawn behavior of the subjects showed reduction in withdrawn behavior of the psychomotricity group and no reduction in the soccer group. Improvements: There is urgent need for research on the reduction in withdrawn behavior within integrated classrooms with students with intellectual disabilities
\end{abstract}

Keywords: Competition, Intellectual Disabilities, Psychomotricity, Soccer Programs, Withdrawn Behavior,

\section{Introduction}

School violence and social discrimination against students with disabilities including intellectual disabilities are occurring in integrated education school environments, and withdrawn behavior is often observed in students with intellectual disabilities ${ }^{1}$.

Integrated education refers to education where students in need of special education is provided with learning suited to their individual educational needs in general schools along with their peers, without being discriminated for the type or the degree of their disabilities ${ }^{2}$.

Psychomotricity, with practice principles of object-centeredness, autonomy, creativity, experienceorientedness, activity-orientedness, recreational activity, subjective constitution of meaning ${ }^{\frac{3.4}{4}}$, was found to have positive effects on reducing problem behaviors ${ }^{5}$.

Studies have found that psychomotricity focusing on physical activities not only improves physical development but also has a positive effect on reducing problem behavior of children ${ }^{6,7}$.

According to ${ }^{\circ}$, It is reported that integrated soccer programs have a positive effect on withdrawn behavior of students with disabilities and integrated physical education is expected to expand opportunities for students with disabilities to interact with nondisabled students in physical education classes in genera schools by maximizing their abilities, as well as opportunities for them to actively participate in physical activities ${ }^{2}$.

${ }^{*}$ Author for correspondence 
In this study, comparative analysis is conducted on withdrawn behavior in peer relations, communication and self-esteem to identify the effects of psychomotricity programs and soccer on the reduction of withdrawn behavior in students with intellectual disabilities.

\section{Materials and Methods}

\subsection{Study Subjects}

students with intellectual disabilities within the age range of 4 th to 6th grades, who are registered at D Motor Development Center in S city and 12 nondisabled students within the age range of 4th to 6th grades from $Y$ Elementary School and D Elementary School (Table 1).

The psychomotricity group and the soccer group were comprised of 12 students, respectively.

All the programs were carried out in integrated environment where students with and without intellectual disabilities were put together, and students without the experience of such an environment were chosen as subjects (Table 2).

Programs were conducted twice a week for 12 weeks from Mar. 30 to Jun. 302015.

\subsection{Measuring Tools and Programs}

The checklist used in the study was based on the research by Oden and Asher (1977) and the research of Kim Young-Hee (2008) was used as reference. Questions that are considered irrelevant by the author of the study were revised or removed, and five psychomotricity experts reviewed and revised the questions.

The checklist used in this study consisted of 14 questions, with the five-point Likert-type scale. A responder can choose one from "Not at All (1 point)," "Not Really (2 point)," "Neutral (3 point)," "Somewhat (4 point)," "Very Much (5 point)." The total point ranges from 14 to 70 . The higher the total point is, the severer withdrawn behavior the responder shows. The checklist showed a Cronbach's alpha reliability coefficient of 0.913 .

Table 1. Result of the test on the homogeneity within groups

\begin{tabular}{|c|c|c|c|}
\hline Variable & $p(n=6)$ & $s(n=6)$ & $\mathrm{p}$ \\
\hline $\begin{array}{c}\text { Withdrawn } \\
\text { behavior }\end{array}$ & $36.83 \pm 1.16$ & $36.50 \pm 1.89$ & .884 \\
\hline
\end{tabular}

Table 2. Research Design

\begin{tabular}{|c|}
\hline Participants \\
\hline Students with \\
intellectual disabilities \\
$(\mathrm{n}=12)$ \\
Nondisabled students \\
$\mathbb{Z}$ \\
$(\mathrm{n}=12)$ \\
\hline Pre-test on \\
ithdrawn behavior \\
\hline
\end{tabular}

\begin{tabular}{|c|c|c|}
\hline $\begin{array}{c}\text { Psychomotricity } \\
\text { group }\end{array}$ & & Soccer group \\
\cline { 1 - 1 } $\begin{array}{c}\text { Students with } \\
\text { intellectual } \\
\text { disabilities }(\mathrm{n}=6)\end{array}$ & $\mathbb{3}$ & $\begin{array}{c}\text { Students with } \\
\text { intellectual disabilities } \\
\text { Nondisabled }\end{array}$ \\
students $(\mathrm{n}=6)$ & & $\begin{array}{c}\text { Nondisabled students } \\
(\mathrm{n}=6)\end{array}$ \\
\cline { 1 - 1 } Psychomotricity & & Soccer \\
\cline { 3 - 3 } & & \\
\hline
\end{tabular}

\begin{tabular}{|ll|}
\hline TABLE I & $\begin{array}{l}\text { Post-test on withdrawn } \\
\text { behavior }\end{array}$ \\
\hline TABLE II & $\begin{array}{l}\text { Students with intellectual } \\
\text { disabilities }(\mathrm{n}=12)\end{array}$ \\
TABLE III & $\begin{array}{l}\text { Nondisabled students } \\
(\mathrm{n}=12)\end{array}$ \\
\hline TABLE IV & $\begin{array}{l}\text { Comparison of mean } \\
\text { values }\end{array}$ \\
\hline
\end{tabular}

\subsection{Data analysis method}

An independent $t$-test was conducted to verify the integrity within groups. SPSS 18.0 program was used to analyze the data. A paired t-test was conducted to compare the pre- and post-test results of the psychomotricity group and the soccer group. ${ }^{*} \mathrm{p}<.05$

\section{Results}

\subsection{Results on Withdrawn Behavior of the Two Groups in Peer Relations}

The results on withdrawn behavior of the two groups in peer relations are shown in Table 3.

In peer relations analysis, there was a meaningful difference between two means in the psychomotricity group, with pre-test $(\mathrm{M}=10.50)$ and post-test $(\mathrm{M}=8.33)$. However, no significant difference was found in the soccer group, with pre-test $(\mathrm{M}=10.83)$ and post-test $(\mathrm{M}=10.33)$ (Table 3). 


\subsection{Results on Withdrawn Behavior of the Two Groups in Communication}

The result on withdrawn behavior of the two groups in communication is shown in Table 4.

In expression ability analysis, a meaningful difference was found in the psychomotricity group, with pre-test $(M=13.66)$ and post-test $(M=11.33)$, while there was no significant difference in the soccer group, with pre-test $(\mathrm{M}=13.33)$ and post-test $(\mathrm{M}=12.83)$ (Table 4).

\subsection{Results on Withdrawn Behavior of the} Two Groups in Self-esteem

The result on withdrawn behavior of the two groups in self-esteem is shown in Table 5.

In self-esteem analysis, the psychomotricity group showed a meaningful difference, with pre-test $(M=12.66)$ and post-test $(\mathrm{M}=11.00)$, while no significant difference was found in the soccer group, with pre-test $(M=12.33)$ and post-test $(\mathrm{M}=11.83)$ (Table 5).

Table 3. Results: The relations

\begin{tabular}{|c|c|c|c|c|c|c|c|}
\hline \multirow{2}{*}{\multicolumn{2}{|c|}{ Group }} & \multicolumn{2}{|l|}{ Pre } & \multicolumn{2}{|l|}{ Post } & \multirow{2}{*}{$t$} & \multirow{2}{*}{$\mathrm{p}$} \\
\hline & & $M$ & $S D$ & $M$ & $S D$ & & \\
\hline \multirow{2}{*}{ Peer relations } & $\mathrm{P}$ & 10.50 & 1.37 & 8.33 & 1.96 & 7.050 & .001 \\
\hline & S & 13.33 & 1.75 & 12.83 & .983 & .745 & .490 \\
\hline
\end{tabular}

${ }^{*} \mathrm{p}<.05$

P: Psychomotricity Groups: Soccer Group

Table 4. Results: The communication

\begin{tabular}{|c|c|c|c|c|c|c|c|}
\hline \multicolumn{2}{|c|}{ Group } & \multicolumn{2}{c|}{ Pre } & \multicolumn{2}{c|}{ Post } & \multirow{2}{*}{$\boldsymbol{*}$} & \multirow{2}{*}{$\mathbf{p}$} \\
\cline { 2 - 6 } & & $M$ & $S D$ & $M$ & $S D$ & & \\
\hline \multirow{3}{*}{ Communication } & $\mathrm{P}$ & 13.66 & .816 & 11.33 & 1.366 & 7.00 & .001 \\
\cline { 2 - 6 } & $\mathrm{S}$ & 13.33 & 1.75 & 12.83 & .983 & .745 & .490 \\
\hline
\end{tabular}

${ }^{*} \mathrm{p}<.05$

P: Psychomotricity Groups: Soccer Group

Table 5. Results: The self-esteem

\begin{tabular}{|c|c|c|c|c|c|c|c|}
\hline \multirow{2}{*}{ Group } & \multicolumn{2}{|c|}{ Pre } & \multicolumn{2}{c|}{ Post } & \multirow{2}{*}{$\boldsymbol{t}$} & \multirow{2}{*}{$p$} \\
\cline { 2 - 6 } & $M$ & $S D$ & $M$ & $S D$ & & \\
\hline \multirow{2}{*}{$\begin{array}{c}\text { Self- } \\
\text { esteem }\end{array}$} & $\mathrm{P}$ & 12.66 & 1.03 & 11.00 & 1.26 & 7.906 & .001 \\
\cline { 2 - 7 } & $\mathrm{S}$ & 12.33 & 2.16 & 11.83 & 2.63 & 1.00 & .363 \\
\hline
\end{tabular}

${ }^{*} \mathrm{p}<.05$

P: Psychomotricity Groups: Soccer Group

\subsection{Results on Overall Withdrawn Behavior of the Two Groups}

The results on results on overall withdrawn behavior of the two groups are shown in Table 6.

According to the analysis on overall withdrawn behavior, a significant difference was found in the psychomotricity group, with pre-test $(M=73.66)$ and post-test $(M=62.00)$, while there was no meaningful difference in the soccer group, with pre-test $(M=73.00)$ and post-test $(\mathrm{M}=71.00)$ (Table 6).

\section{Discussion}

This study compared and analyzed the effects or psychomotricity and soccer programs in an integrated environment by measuring the frequency of withdrawn behavior of the subjects.

The results of the study can be summarized as follows.

The tests on withdrawn behavior of the subjects in peer relations showed reduction in withdrawn behavior of the psychomotricity group and no reduction in the soccer group.

The tests on withdrawn behavior of the subjects in communication showed reduction in withdrawn behavior of the psychomotricity group and no reduction in the soccer group.

The tests on withdrawn behavior of the subjects in self-esteem showed reduction in withdrawn behavior of the psychomotricity group and no reduction in the soccer group.

A study has shown that psychomotricity is more effective than soccer in improving the initiative of withdrawn early-children by ${ }^{10}$ and reducing withdrawn behavior among the problem behavior of the children.

It seems that psychomotor programs, which are recreational activities that do not encourage competition,

Table 6. Results: The overall withdrawn behavior

\begin{tabular}{|c|c|c|c|c|c|c|c|}
\hline \multirow{2}{*}{ Group } & \multicolumn{2}{|c|}{ Post } & \multicolumn{2}{c|}{ Post } & \multirow{2}{*}{$\boldsymbol{t}$} & \multirow{2}{*}{ p } \\
\cline { 2 - 8 } & $M$ & $S D$ & $M$ & $S D$ & & \\
\hline \multirow{2}{*}{$\begin{array}{c}\text { Withdrawn } \\
\text { behavior }\end{array}$} & $\mathrm{P}$ & 73.66 & 9.71 & 62.00 & 10.39 & 6.286 & .024 \\
\cline { 2 - 8 } & $\mathrm{S}$ & 73.00 & 7.549 & 71.00 & 9.000 & 2.00 & .184 \\
\hline
\end{tabular}

${ }^{*} \mathrm{p}<.05$

P: Psychomotricity Group,S: Soccer Group 
have effects on reducing withdrawn behavior in students with intellectual disabilities. However, soccer programs, which encourage competition, do not seem to be effective in reducing withdrawn behavior.

Based on this study, some suggestions can be made for follow-up research.

First, this study did not include control groups other than the psychomotricity group and the soccer group. Therefore, a research standard should be made through studying control groups in follow-up research.

Second, this study had a limitation of having small numbers of subjects for both the psychomotricity group and the soccer group. More students with intellectual disabilities and withdrawn behavior for various types of disabilities should be studied in follow-up research.

Third, more accurate measurement and study on withdrawn behavior are needed through follow-up research on test instruments that help observe and measure withdrawn behavior of students with intellectual disabilities.

Fourth, there is urgent need for research on the reduction in withdrawn behavior within integrated classrooms with intellectually disabled students. Further research is needed on various psychomotricity programs and their effects ${ }^{11}$.

There is urgent need for research on the reduction in withdrawn behavior within integrated classrooms with students with intellectual disabilities. Further research is needed on various psychomotricity programs and their effects.

\section{References}

1. National Institute of Special Education [Internet]. [cited 2014]. Available from: https://www.nise.go.jp/cms/ resources/content/835/Special_Education_in_Japan.pdf.
2. Ministry of Education and Human Resources Development [Internet]. [cited 2016]. Available from: http://ministry-education.govmu.org/English/Pages/default.aspx.

3. Kiphard E J. Motopdagogik. Dortmund; 1987.

4. Zimmer, R. A point of view child-centered on psychomotorik. Ins Psychomotorik on Koera; 2005. p. 5-35.

5. Yun-Jeong K. Effect of psychomotor physical activity program on body perception and problem behavior of autistic students. Graduate School of Sport Rehabilitation Science, Hanshin University; 2011.

6. Mi JS. The effects of psychomotorik on social competence of high schooler with intellectual disabilies. Graduate School of Special Education. Dankook University; 2014.

7. Tae SY, Cheon JK. Effect of a psychomotor program on the motor performance abilities of students with autism. Korean Journal of Exercise Rehabilitation. 2011; 7(1):69-78.

8. Jung RY. The effect of the inclusive soccer program on the social distance of children without disability toward people with disability, and withdrawn behavior of children with disability. Graduate School of Physical Education. Seoul National University; 2015.

9. Jun YH. Physical activity level and interaction of students with mild physical disabilities placed in inclusive middle school physical education classes. Korean Journal of Adapted Physical Activity. 2014; 22(3):43-63.

10. Jeong PS. Effects of psychomotoric play on initiative of withdrawn early-children. Graduate School of Special Education. Dankook University; 2013.

11. Haemi K. Effect of psychomotricity by ADHD children on the ego-resilience and social relation skill of convergence. Indian Journal of Science and Technology. 2016; 9(26):1-5. 